\title{
Tubulin inhibitor AEZS 112 inhibits the growth of experimental human ovarian and endometrial cancers irrespective of caspase inhibition
}

\author{
JÖRG B. ENGEL, TANJA SCHÖNHALS, CLAUDIA WEIDLER, SEBASTIAN HÄUSLER, \\ MATHIAS KROCKENBERGER, LORENZ RIEGER, JOHANNES DIETL, \\ JÖRG WISCHHUSEN and ARND HONIG
}

Universitätsfrauenklinik Würzburg, Josef-Schneider-Strasse 4, D-97080 Würzburg, Germany

Received January 19, 2009; Accepted April 2, 2009

DOI: 10.3892/or_00000446

\begin{abstract}
AEZS 112 is an orally active small molecule anticancer drug which inhibits the polymerization of tubulin at low micromolar concentrations. The current study investigates the anti-tumor effect and the mechanism of action of AEZS 112 in in vitro models of human ovarian and endometrial cancers. Four human ovarian and 2 endometrial cancer cell lines were incubated with increasing concentrations of AEZS 112 with and without multi-caspase inhibitor zVAD-FMK for 72 hours. Cytotoxic effects of AEZS 112 were analyzed using crystal violet staining, FACS analysis of DNA content as well as Annexin V/propidium iodide-double staining. AEZS 112 displayed anti-tumor activity in all six cell lines. The EC50 determined after 72-h incubation for Ishikawa and HEC 1A was 0.0312 and $0.125 \mu \mathrm{M}$, respectively. The EC50 was $5 \mu \mathrm{M}$ for SKOV 3 cells, $1 \mu \mathrm{M}$ for $0.5 \mu \mathrm{M}$ for OAW 42 cells, $0.125 \mu \mathrm{M}$ for OvW 1 cells and $0.0312 \mu \mathrm{M}$ for PA 1 cells. Cytotoxic effects of AEZS 112 could not be abrogated by caspase inhibition with pan-caspase inhibitor zVAD-fmk. Annexin V/propidium iodide-double staining after treatment with AEZS 112 was indicative of necrosis-like cell death. AEZS 112 dose-dependently increased non-vital hypodiploid cells and the cytotoxic effect was least pronounced in G2 phase of the cell cycle, indicating cell death during mitosis, as determined by FACS analysis. The orally active small molecule tubulin inhibitor AEZS 112 showed anti-tumor activity in human ovarian and endometrial cancer cell lines at low micromolar concentrations, which could not be abrogated by caspase inhibition and is therefore a good candidate for in vivo studies in these tumors.
\end{abstract}

Correspondence to: Dr Jörg B. Engel, Universitätsfrauenklinik Würzburg, Josef-Schneider-Strasse 4, D-97080 Würzburg, Germany E-mail: joergbengel@hotmail.com

Key words: oral tubulin inhibitor, AEZS 112, endometrial cancer cells, ovarian cancer cells, apoptosis, caspase inhibition, cytotoxicity

\section{Introduction}

Novel cytotoxic compounds that interfere with the cell cycle are a subject of major interest in cancer research. Tubulin is a ubiquitous protein that plays an important role during cell division (1). Thus, inhibition of tubulin polymerization induces G2/M arrest and subsequent cell death (2).

AEZS 112 is an orally active small molecule anticancer drug with several mechanism of action, such as DNA fragmentation via inhibition of topoisomerase II as well as inhibition of tubulin polymerization. It has been shown to inhibit the polymerization of tubulin in low micromolar concentration. Competition experiments suggest that AEZS 112 interacts at the colchicine binding-site of the microtubules, thus destroying the mitotic spindle. AEZS 112 has shown in vitro activity in a variety of tumors such as breast and prostatic cancers.

Late stage ovarian and endometrial cancer are associated with a dismal prognosis (3). In adjuvant and palliative treatment of ovarian cancer tubulin inhibitors, namely the taxanes are highly active and one of the pillars of systemic therapy $(4,5)$. Likewise in advanced endometrial carcinoma combination regimens combining a platinum compound and paclitaxel are frequently used $(6,7)$.

The good anti-tumor activity of the taxanes in both tumor entities prompted us to test the novel orally active tubulin inhibitor AEZS 112 for the first time in experimental models of human ovarian and endometrial cancers.

\section{Materials and methods}

Reagents and cell lines. AEZS 112 (ZEN 012) was kindly provided by Aeterna Zentaris GmbH (Frankfurt, Germany). HEC1A and Ishikawa human endometrial cancer cells were obtained from American Type Culture Collection (Manassas, VA, USA). Ovarian cancer cell lines SKOV 3, OAW 42, PA 1 and OvW 1 were also obtained from American Type Culture Collection. HEC1A cells were grown in RPMI-1640 medium (PAA, Cölbe, Germany). Ishikawa cells were cultured in Dulbecco's modified Eagle's medium (DMEM) (PAA) containing $10 \%$ fetal calf serum, $2 \mathrm{mM}$ glutamine, and $1 \%$ penicillin/streptomycin, $0.5 \%$ sodium pyruvate solution (PAA). 
The ovarian cancer cells were cultured in Dulbecco's modified Eagle's medium (DMEM) containing 10\% fetal calf serum, $2 \mathrm{mM}$ glutamine, and $1 \%$ penicillin/streptomycin. Primary human peripheral blood lymphocytes (PBL) were obtained by venipuncture from healthy individuals and purified by density gradient centrifugation (Biocoll, Biochrom). Cells were maintained in X-Vivo 15 (Lonzar, Bioscience, Vervier, Belgium). The broad spectrum caspase inhibitor (benzyloxycarbonyl-val-ala-asp (OMe)-fluoromethylketone) zVAD-fmk was from Bachem (Weil am Rhein, Germany), mega FAS Ligand from Alexis (San Diego, CA, USA) and AnxV-FITC (Annexin) was obtained from PharMingen (Heidelberg, Germany). PI and all other reagents, unless indicated otherwise, were purchased from Sigma (St. Louis, MO, USA).

Viability assays. For acute cytotoxicity assays, the cells were seeded at $1=10^{4}$ cells per well in 96-well plates, adherend for $24 \mathrm{~h}$, and exposed to the drugs for 24-72 h. The cell lines doubled twice, and grew exponentially within the time frame of this experiment. Proliferation was assessed by crystal violet staining (8). Briefly, the cell culture medium was removed and surviving cells stained with $0.5 \%$ crystal violet in $20 \%$ methanol for $20 \mathrm{~min}$ at room temperature. The plates were washed extensively under running tap water, air dried and optical density values read in an enzyme-linked immunosorbent assay ELISA reader at wavelength at $550 \mathrm{~nm}$ wavelength. EC values were derived from graphic extrapolation.

Immunoblot analysis. The general procedure has been described (9). The cells were untreated or treated with AEZS 112 as indicated and lysed. Soluble protein levels were analysed by immunoblot using $20 \mathrm{mg}$ of protein per lane separated on 10-12\% acrylamide gels (BioRad, Munich, Germany). After transfer to a nitrocellulose membrane, the blots were pretreated for $2 \mathrm{~h}$ with phosphate-buffered saline (PBS) containing 5\% skim-milk and $0.05 \%$ Tween-20, and then incubated overnight at $41^{\circ} \mathrm{C}$ with the anti-PARP antibody (clone 4C10-5, \#556494, PharMingen-BectonDickinson Heidelberg, Germany). Visualization of protein bands was accomplished using hoseradish pero-xidase (HRP)-coupled IgG secondary antibody (Sigma) and enhanced chemiluminescence (ECL) (Amersham, Braunschweig, Germany).

Flow cytometry for cell cycle analysis and for Annexin $V$ FITC/propidium iodide (AnxV-FITC/PI). For cell cycle analysis, the endometrial cancer cells were treated with perifosine as indicated, harvested, fixed and permeabilized overnight in ice-cold $70 \%$ ethanol (Merck, Darmstadt, Germany). The cells were washed twice with PBS. RNA was digested with RNase A (Gibco Life Technologies, Paisley, UK). The DNA was stained with PI $(50 \mu \mathrm{g} / \mathrm{ml})$. Fluorescence was recorded on channel Fl-2A in a FACScalibur (Becton-Dickinson). Instrument settings were adjusted to move the G1 peak to 200 relative fluorescence units. Cells to the left of this peak appeared to have a DNA content below $2 n$, indicative of cell death. Aggregated cells were detected in channel F1-2W and gated out. A total of 10,000 events per condition were recorded. Evidence for apoptosis was also obtained by AnxV-FITC staining that measures the exposure of phophatidylserine on the cell membrane. The cells were collected, washed with PBS and resuspended in a buffer containing $10 \mathrm{mM}$ HEPES/NaOH, pH 7.4, $140 \mathrm{mM} \mathrm{NaCl}$ and $2.5 \mathrm{mM} \mathrm{CaCl}_{2}$. AnxV-FITC (1:100) (Annexin) and PI $(50 \mu \mathrm{g} / \mathrm{ml})$ were added.

\section{Results}

Treatment of human endometrial and ovarian cancer cells with AEZS 112. Human endometrial cancer cell lines Ishikawa and HEC 1A were incubated with AEZS 112 at 0.0312 , $0.0625,0.125,0.25,0.5$ and $1 \mu \mathrm{M}$ for 48 and $72 \mathrm{~h}$. All experiments were repeated at least in triplicates. The EC50 determined after 72-h incubation for Ishikawa and HEC 1A endometrial cancer cells was 0.0312 and $0.125 \mu \mathrm{M}$, respectively (Fig. 1).

Human ovarian cancer cell lines OAW 42, OvW1 and PA 1 cells were incubated with AEZS 112 at $0.0312,0.0625$, $0.125,0.25,0.5$ and $1 \mu \mathrm{M}$ for $72 \mathrm{~h}$. SKOV 3 cells were incubated at $0.156,0.312,0.625,1.25,2.5$ and $5 \mu \mathrm{M}$ for $72 \mathrm{~h}$. All experiments were repeated at least in triplicates. The EC50 determined after 72-h incubation was $5 \mu \mathrm{M}$ for SKOV 3 cells, $1 \mu \mathrm{M}$ for $0.5 \mu \mathrm{M}$ for OAW 42 cells, $0.125 \mu \mathrm{M}$ for OvW 1 cells and $0.0312 \mu \mathrm{M}$ for PA 1 cells (Fig. 1). After 24 h however, only a minimal treatment effect of AEZS 112 was seen in HEC 1A, SKOV 3 and OAW 42 cells, indicating time-dependency of the cytotoxic effect (data not shown). Likewise serum starvation pronouncedly diminished the cytotoxicity of AEZS 112 as demonstrated in HEC 1A, OAW 42, OvW 1, SKOV 3 and PA 1 cells (data not shown).

AEZS 112 induces cleavage of poly(ADP-ribose) polymerase $(P A R P)$. We analyzed poly(ADP-ribose) polymerase (PARP) cleavage with and without treatment of human ovarian cancer cells with AEZS 112. AEZS 112 induced cleavage of PARP in human ovarian cancer cells, whereas untreated cells did not reveal any PARP-cleavage (Fig. 2).

Co-incubation with multi-caspase inhibitor zVAD-fmk does not decrease the cytotoxic effect of AEZS 112. In order to investigate if inhibition of caspases abrogates the cytotoxic effect of AEZS 112 we co-incubated multi-caspase inhibitor zVAD-fmk $(50 \mu \mathrm{M})$ with AEZS 112 at $0.125,0.25,0.5$ and $1 \mu \mathrm{M}$ for $72 \mathrm{~h}$ in HEC-1a, SKOV-3, OAW 42 and PA-1 cells. However, cytotoxicity of AEZS 112 was not decreased in any of the cell lines investigated (Fig. 3).

Analysis of markers of apoptosis and necrosis by fluorescence activated cell sorting (FACS). We explored the mode of cell death by Annexin V-FITC/propidium iodide (AnxV-FITC/PI) FACS analysis. Early apoptotic cells are Annexin V-FITC positive and an increase in propidium iodide (PI) uptake precedes the loss of membrane integrity suggesting necrosis-like cell death. Annexin V-FITC and propidium iodide (PI) uptake would be suggestive of late apoptosis.

The FACS labeling revealed that AEZS $112(0.25 \mu \mathrm{M}$, $1 \mu \mathrm{M})$ induced a dose-dependent increase of the propidium 
(A)

Ishikawa

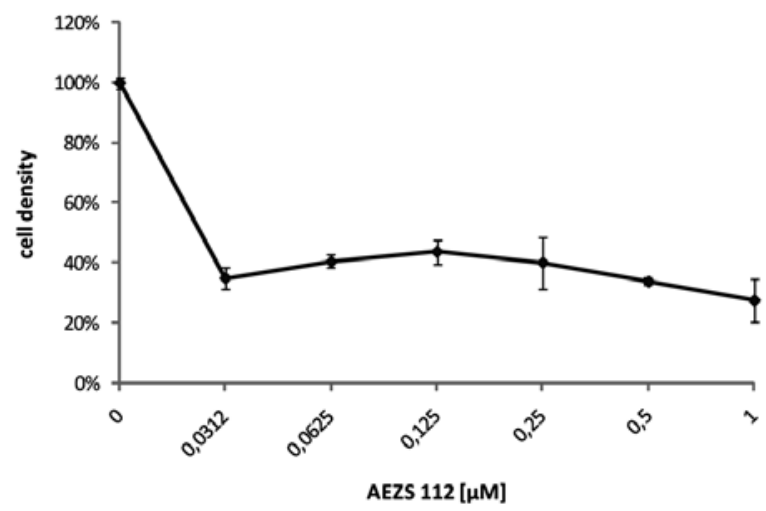

(C)

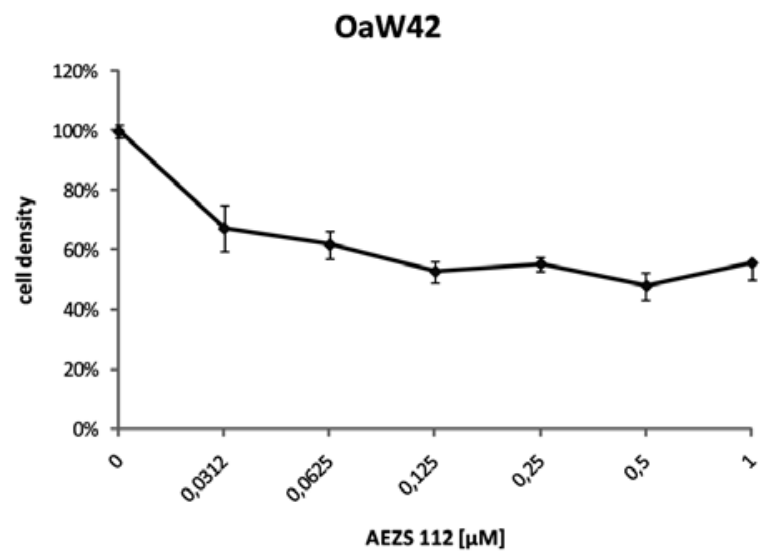

(E)

OaW-1

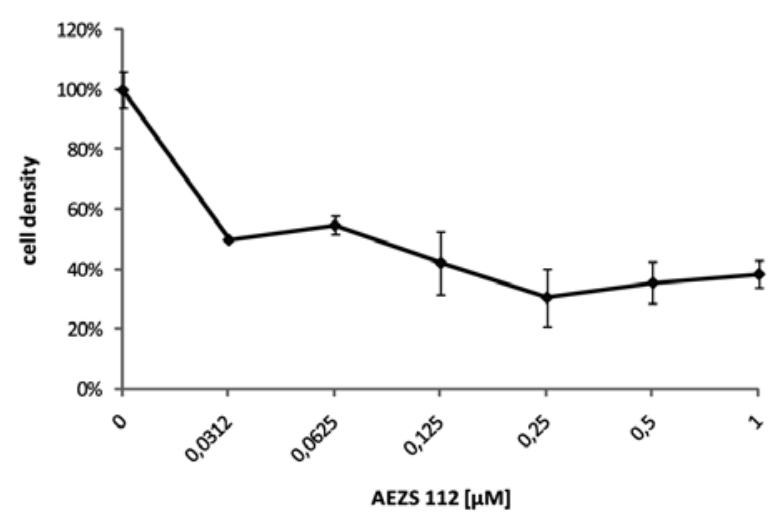

(B)

HEC-1a

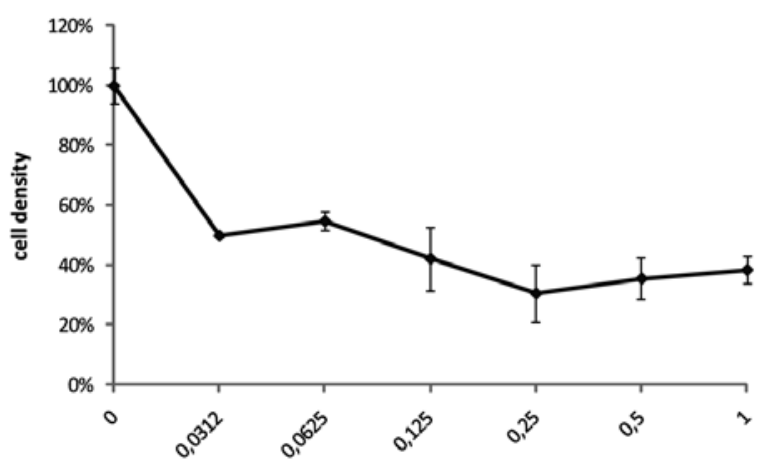

AEZS $112[\mu \mathrm{M}]$

(D)

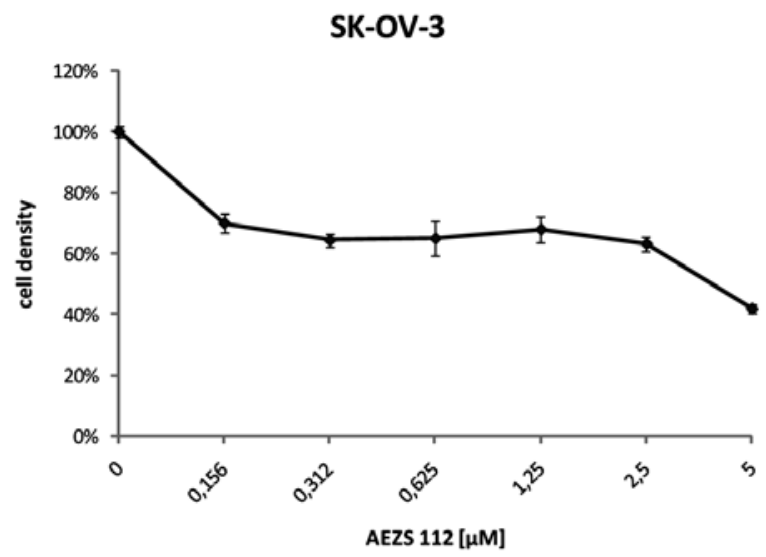

(F)

PA-1

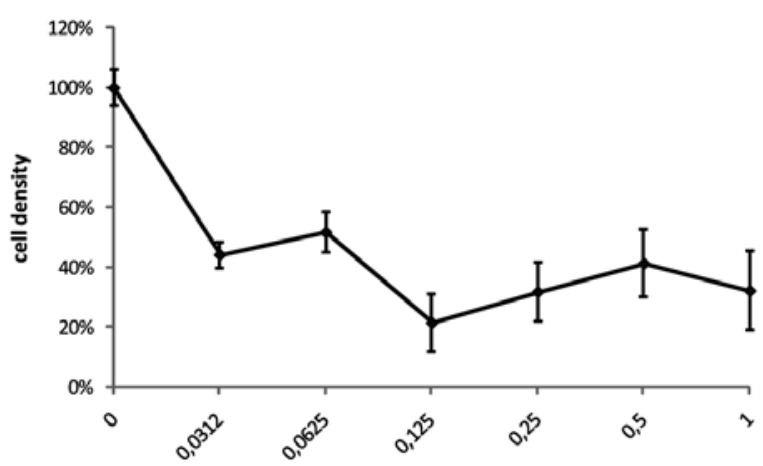

AEZS 112 [ $\mu \mathrm{M}]$

Figure 1. Effect of AEZS 112 on the proliferation of Ishikawa (A), HEC-1A (B), OAW 42 (C), SKOV 3 (D), OvW 1 (E), and PA 1 (F) human ovarian cancer cells. Cells were incubated with AEZS 112 at different concentrations for $72 \mathrm{~h}$. These experiments are representative of three independent experiments, each performed in triplicate wells. Relative cell number in treated and control wells was determined by crystal violet staining and expressed as percent T/C values, where $\mathrm{T}$, absorbance of treated cultures and $\mathrm{C}$, absorbance of control cultures.

iodide positive cell fraction in OAW-42, OvW-1 and PA-1 cells suggesting an AEZS 112 induced loss of membrane integrity (Table I). There was only a negligible increase of Annexin positive cells mediated by the co-incubation with AEZS 112 at 0.25 and $1 \mu \mathrm{M}$ (Table I).
DNA cell cycle analysis by fluorescence-activated cell sorting (FACS). The percentage of each cell cycle phase and the sub-G0 group (i.e. the dead cells) were examined and determined by flow cytometric analysis in all lines. Endometrial cancer cells Ishikawa and HEC1A were submitted 


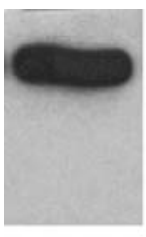

ctrl.

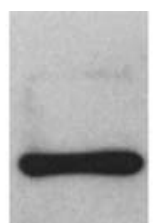

mega-

FasLigand

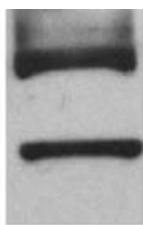

AEZS 112

$(0,25 \mu \mathrm{M})$

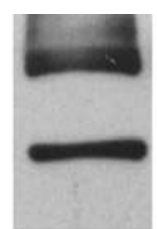

$119 \mathrm{kD}$

$84 \mathrm{kD}$

Figure 2. Effect of AEZS 112 at different concentrations on the cleavage of PARP in OAW-42 human ovarian cancer cells as determined by Western blotting. The $119 \mathrm{kDa}$ protein corresponds to the uncleaved form of PARP and the second protein running at $84 \mathrm{kDa}$ protein is the cleaved form of PARP. Only the uncleaved $119 \mathrm{kDa}$ protein is visible in untreated control cells. In lane 1 FAS ligand, a known inductor of apoptosis via the extrinsic pathway, is used as a positive control.

(A)

HEC-1a

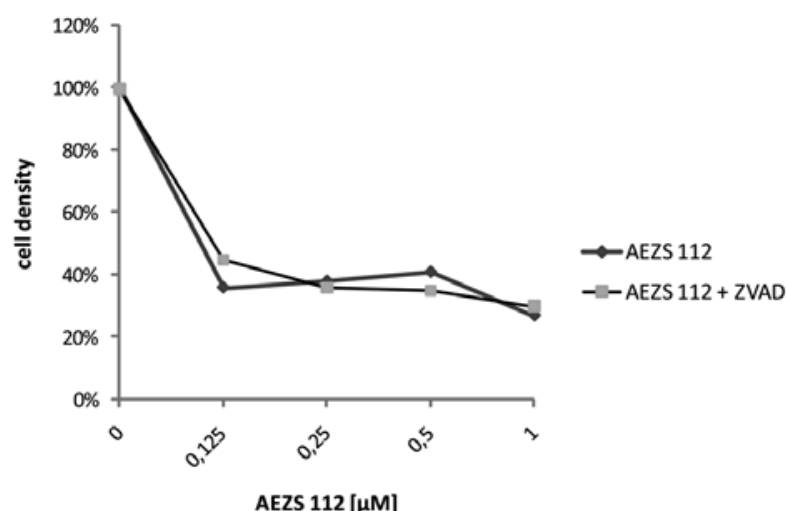

(C)

SK-OV-3

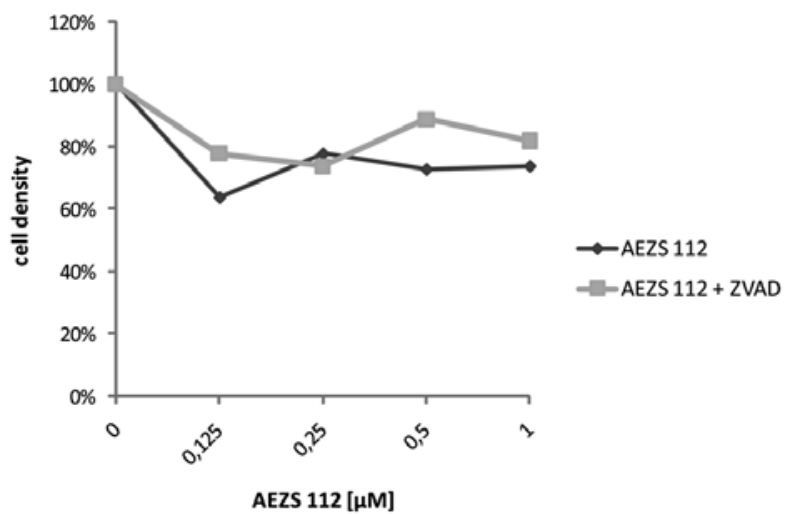

(B)

AEZS 112

$(1 \mu \mathrm{M})$ 
(A)

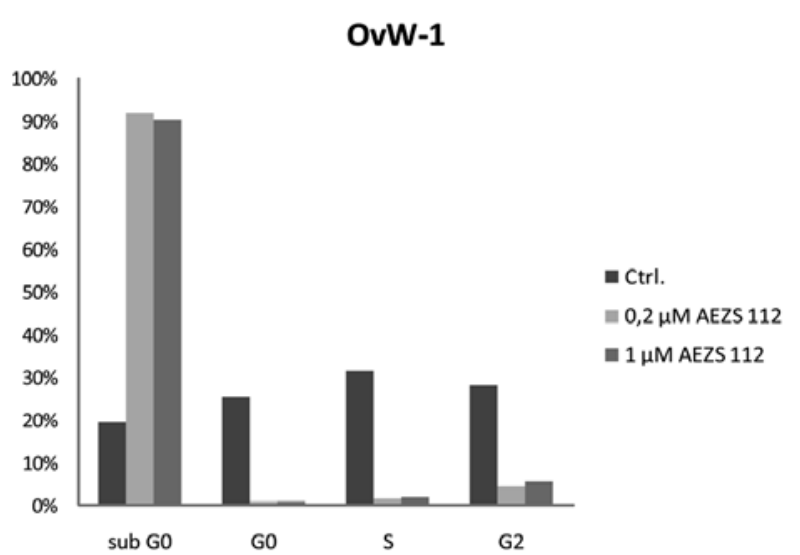

(C)

HEC-1a

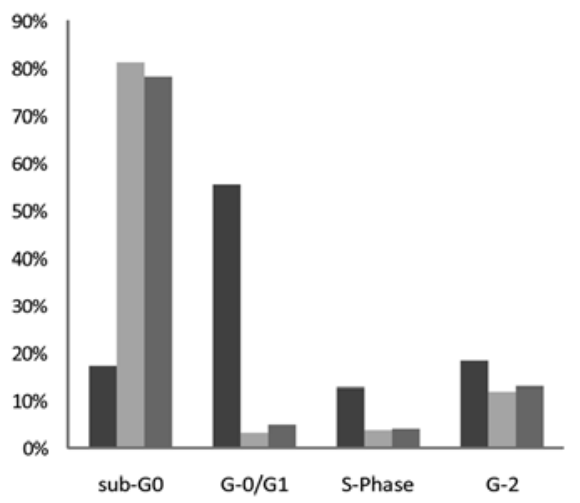

$(\mathrm{E})$

PBL

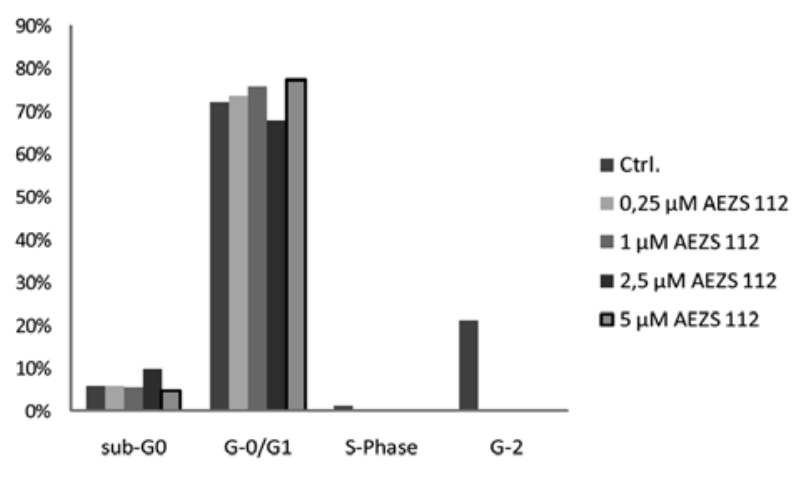

isolated PBL were cultivated in the presence of increasing concentrations of AEZS $112(0.5-5 \mu \mathrm{M})$. DNA cell cycle distribution was analyzed by flow cytometry. Even the highest concentration of AEZS 112 tested it did not increase the number of non-vital cells as compared to untreated control PBL.

$=0,25 \mu \mathrm{M}$ AEZS 112

- $1 \mu \mathrm{M}$ AEZS 112
(B)

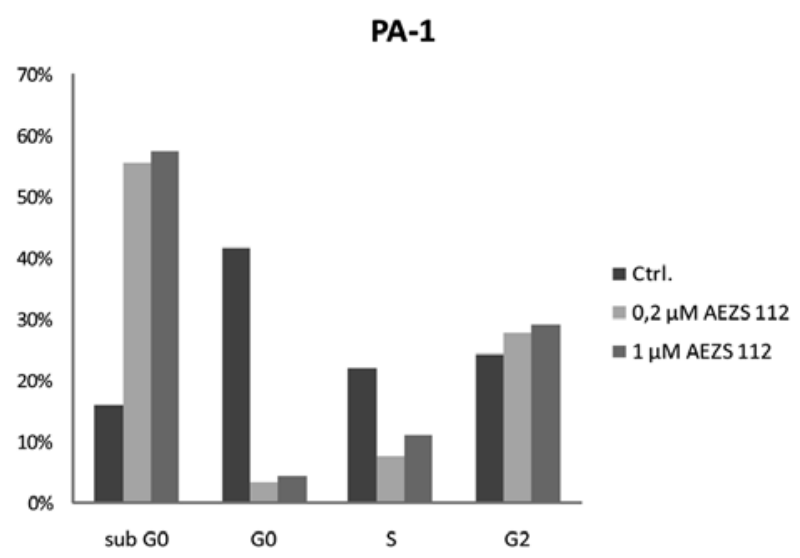

(D)

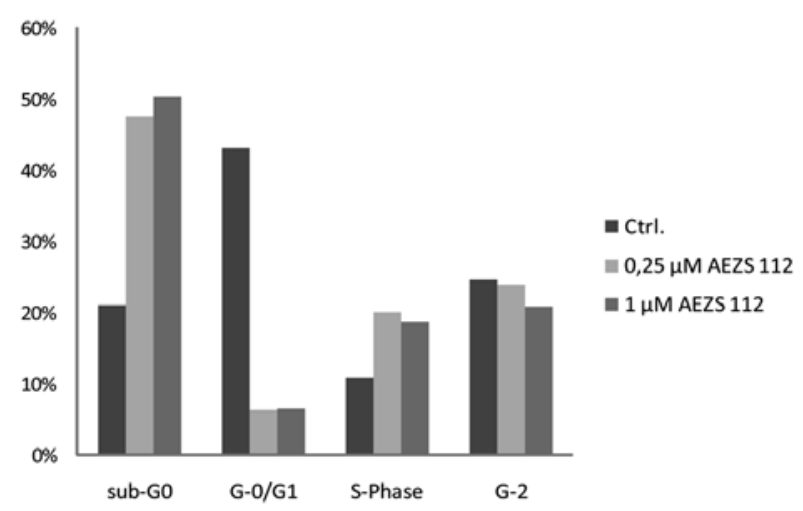

Figure 4. (A-D) Effect of different concentrations of AEZS 112 on the distribution of OVW1, PA1, HEC1A and Ishikawa cells throughout the cell cycle as determined by FACS analysis. Sub/G0 fraction (i.e. dead cells increase dose dependently. Cytotoxic effect is least pronounced in G2 phase of the cell cycle, indicating cell death during mitosis. (E) Effect of different concentrations of AEZS 112 on the distribution of peripheral blood lymphocytes throughout the cell cycle as determined by FACS analysis. No increase of cells in the sub G0 phase indicating cytotoxicity occurred.

\section{Discussion}

Our experiments demonstrate good antitumor activity of AEZS 112 at doses in the low micromolar or nanomolar range in four ovarian and two endometrial cancer cell lines as demonstrated by crystal violet staining and FACS analysis. Cytoxicity of AEZS 112 was confined to dividing cells, as serum starvation nullified growth inhibition. FACS analyses showed that AEZS 112 induces cell death rather in the M phase of the cell cycle, as the treatment effect was least pronounced 
Table I. Mode of cell death as demonstrated by Annexin $\mathrm{V}$-FITC/propidium iodide (AnxV-FITC/PI) FACS analysis.

\begin{tabular}{cccc}
\hline OAW-42 & Control & AEZS 112 & AEZS 112 \\
& $(\%)$ & $0.25 \mu \mathrm{M}(\%)$ & $1 \mu \mathrm{M}(\%)$
\end{tabular}

\section{$24 \mathrm{~h}$}

\section{PJ-Ann-}

PJ-Ann+

PJ+Ann-

$\mathrm{PJ}+\mathrm{Ann}+$

$38 \mathrm{~h}$

\subsection{2}

1.67

9.44

0.57

88.32
1.67
9.44
0.57

88.32

PJ-Ann+

PJ+Ann-

PJ+Ann+

OvW-1

$24 \mathrm{~h}$

\section{PJ-Ann-}

PJ-Ann+

PJ+Ann-

PJ+Ann+

$38 \mathrm{~h}$

$\begin{array}{lcrc}\text { PJ-Ann- } & 92.6 & 82.59 & 81.35 \\ \text { PJ-Ann+ } & 0.67 & 0.12 & 0.22 \\ \text { PJ+Ann- } & 6.49 & 17.11 & 18.21 \\ \text { PJ+ Ann+ } & 0.23 & 0.19 & 0.22\end{array}$

PA-1

$24 \mathrm{~h}$

PJ-Ann-

PJ-Ann+

PJ+Ann-

PJ+Ann+

$38 \mathrm{~h}$

\begin{tabular}{crrr} 
PJ-Ann- & 88.51 & 50.66 & 46.5 \\
PJ-Ann+ & 1.39 & 6.78 & 8.1 \\
PJ+Ann- & 9.72 & 40.96 & 43.83 \\
PJ+Ann+ & 0.39 & 1.66 & 1.56 \\
PJ-Ann- & Vital cells & & \\
PJ-Ann+ & Apoptosis & & \\
PJ+Ann- & Necrosis & & \\
PJ+Ann+ & Late apoptosis & & \\
\hline
\end{tabular}

Early apoptotic cells are Annexin V-FITC positive and an increase in propidium iodide (PI) uptake precedes the loss of membrane integrity suggesting necrosis-like cell death. Annexin V-FITC and propidium iodide (PI) uptake would be suggestive for late appotosis. The FACS labeling revealed that AEZS $112(0.25 \mu \mathrm{M}$, $1 \mu \mathrm{M}$ ) induced a dose-dependent increase of the propidium iodide positive cell fraction in OAW-42, OvW-1 and PA-1 cells suggesting necrosis-like cell death.

in the G2 phase. These data are in good accordance with the inhibition of tubulin polymerization as the main mechanism of action of AEZS 112.
In order to elucidate how AEZS 112 induces cell death we demonstrated that treatment induces PARP cleavage suggestive for classical apoptosis. Additionally, we evaluated the effect of co-administration of the multi-caspase inhibitor zVAD-FMK with AEZS 112. Surprisingly, cell death could not be inhibited by zVAD-FMK. Likewise, AnnexinV/ propidium iodide-double staining failed to demonstrate a significant population of cells undergoing classical apoptosis, but was suggestive of atypical apoptosis or necrosis. As treatment with AEZS 112 certainly induces cell death as reflected by our crystal violet assays and our FACS analyses, we interpret this finding as follows. Previous studies investigating the mechanism by which taxanes induce cell death found that these tubulin inhibitors can induce classical apoptosis, but are also capable of inducing non-classical caspaseindepenent apoptosis (10). Furthermore, necrosis-like cell death after taxane treatment has been described and was explained as follows (11). The disruption of mitotic cell division by the drug's inhibition of the dynamic reorgan ization of microtubules results in the activation of the mitotic spindle checkpoint in tumor cells. When damage to the mitotic apparatus is excessive, the checkpoint will eventually release without the mitotic machinery being repaired; if the checkpoint is completely or partially defective, the cell will arrest transiently or proceed through mitosis without arresting $(12,13)$. The damage causes the improper segregation of chromosomes resulting in aberrant mitosis and an eventual necrosis-like cell death. Taken together, the cellular death response triggered by cytotoxic agents depends on the type and dose of chemotherapeutic stress and the cell system investigated and may involve classic apoptosis, as well as various types of apoptotic or necrotic programmed cell death $(10,14)$. Blagosklonny and coworkers demonstrated that Jurkat leukemia cells underwent apoptosis following treatment with paclitaxel, whereas MDA-MB-231 breast cancer cells underwent a non-apoptotic cell death (15). Given the fact that AEZS 112 also inhibits tubuline polymerization, necrosis like cell death may be the most relevant cytotoxic mechanism in the cell lines we investigated.

In conclusion, we demonstrated for the first time that orally active tubulin inhibitor AEZS 112 has a pronounced cytotoxic effect in a broad range of endometrial and ovarian cancer cells at nanomolar concentrations and is a good candidate for in vivo studies in these tumor entities.

\section{References}

1. Luduena RF, Banerjee A and Khan IA: Tubulin structure and biochemistry. Curr Opin Cell Biol 4: 53-57, 1992.

2. Dumontet C and Sikic BI: Mechanisms of action of and resistance to antitubulin agents: microtubule dynamics, drug transport, and cell death. J Clin Oncol 17: 1061-1070, 1999.

3. Aalders JG, Abeler V and Kolstad P: Recurrent adenocarcinoma of the endometrium: a clinical and histopathological study of 379 patients. Gynecol Oncol 17: 85-103, 1984.

4. Marsh S and McLeod HL: Pharmacogenetics and oncology treatment for breast cancer. Expert Opin Pharmacother 8: 119-127, 2007.

5. Bhoola S and Hoskins WJ: Diagnosis and management of epithelial ovarian cancer. Obstet Gynecol 107: 1399-1410, 2006.

6. Humber C, Tierney J, Symonds P, Collingwood M, Kirwan J, Williams C and Green J: Chemotherapy for advanced, recurrent or metastatic endometrial carcinoma. Cochrane Database Syst Rev:CD003915, 2005. 
7. Humber CE, Tierney JF, Symonds RP, Collingwood M, Kirwan J, Williams C and Green JA: Chemotherapy for advanced, recurrent or metastatic endometrial cancer: a systematic review of Cochrane collaboration. Ann Oncol 18: 409-420, 2007.

8. Weller M, Rieger J, Grimmel C, Van Meir EG, De Tribolet N, Krajewski S, Reed JC, von Deimling A and Dichgans J: Predicting chemoresistance in human malignant glioma cells: the role of molecular genetic analyses. Int J Cancer 79: 640-644, 1998.

9. Naumann U and Weller M: Retroviral BAX gene transfer fails to sensitize malignant glioma cells to CD95L-induced apoptosis and cancer chemotherapy. Int J Cancer 77: 645-648, 1998.

10. Broker LE, Kruyt FA and Giaccone G: Cell death independent of caspases: a review. Clin Cancer Res 11: 3155-3162, 2005.
11. Morse DL, Gray H, Payne CM and Gillies RJ: Docetaxel induces cell death through mitotic catastrophe in human breast cancer cells. Mol Cancer Ther 4: 1495-1504, 2005.

12. Lanni JS and Jacks T: Characterization of the p53-dependent postmitotic checkpoint following spindle disruption. Mol Cell Biol 18: 1055-1064, 1998.

13. Vogel C, Kienitz A, Hofmann I, Muller R and Bastians H: Crosstalk of the mitotic spindle assembly checkpoint with p53 to prevent polyploidy. Oncogene 23: 6845-6853, 2004.

14. Leist $\mathrm{M}$ and Jaattela $\mathrm{M}$ : Four deaths and a funeral: from caspases to alternative mechanisms. Nat Rev Mol Cell Biol 2: 589-598, 2001.

15. Blagosklonny MV, Robey R, Sheikh MS and Fojo T: Paclitaxelinduced FasL-independent apoptosis and slow (non-apoptotic) cell death. Cancer Biol Ther 1: 113-117, 2002. 